\title{
Psychosocial indicators among aircraft maintenance workers with and without neck and shoulder musculoskeletal symptoms
}

\author{
Oliveira, $\mathrm{A}^{\mathrm{a}, \mathrm{b}}$; Nogueira, $\mathrm{H}^{\mathrm{a}^{*}}$; Diniz, $\mathrm{A}^{\mathrm{b}}$ and Barbieri, $\mathrm{D}^{\mathrm{a}}$ \\ a Graduate Program in Physical Therapy, Universidade Federal de São Carlos UFSCar, São Paulo,Brazil \\ ${ }^{\mathrm{b}}$ Undergraduate Program in Physical Therapy, Universidade Federal de São Carlos UFSCar, São Paulo, Brazil
}

\begin{abstract}
In the aircraft maintenance industry, most of workers performs manual handling tasks of different materials, varying from small objects up to large pieces of the aircraft. It can increase the occurrence of work-related musculoskeletal disorders (WMSDs), which are strongly associated with high physical demands required by the task. Moreover, psychosocial demands are considered as risk factors for musculoskeletal disorders in both the upper limbs and lumbar spine. Thus, the objective of this study was to assess psychosocial indicators among aircraft maintenance workers according to the presence of neck and shoulder musculoskeletal symptoms. Eighty workers of an aircraft maintenance company were evaluated (32.69 \pm 8.25 years, $79.8 \pm 13.4 \mathrm{~kg}, 175 \pm 7 \mathrm{~cm}$ ). According to physical examination, 50 workers were classified as asymptomatic (AS $-4.1 \pm 3.17$ positive signs) whilst 30 workers were classified as symptomatic (SS - 26.72 \pm 11.44 positive signs). AS and SS have shown similar profile of demand $(p=0.62)$, control $(p=0.66)$ and social support $(p=0.74)$ according to the Job Content Questionnaire. However, the groups are different when considering work engagement variables. In general, SS have higher scores than AS $(p<0.05)$.
\end{abstract}

Keywords: Physical therapy; prevention; ergonomics; WRMD; aviation.

\section{Introduction}

In the aircraft maintenance industry, most of workers performs manual handling tasks according to working demand, leading to a typical imbalance between the imposed load and their functional capacity $[8,16]$. These features can increase the occurrence of musculoskeletal disorders (MSDs), which are strongly associated with high physical demands required by the task [18].

Moreover, psychosocial demands are considered as risk factors for musculoskeletal disorders in both the upper limbs and lumbar spine [15, 18]. However, studies focusing on the aircraft maintenance industry and workers' psychosocial conditions are scarce and impair the adoption of preventive measures. Thus, the objective of this study was to assess psychosocial indicators among aircraft maintenance workers according to presence of neck and shoulder musculoskeletal symptoms.

\section{Methods}

Eighty workers of an aircraft maintenance company were evaluated $(32.69 \pm 8.25$ years, $79.8 \pm 13.4$ $\mathrm{kg}, 175 \pm 7 \mathrm{~cm})$. The tasks performed by these workers are mainly related to manual material handling (varying from small objects to large pieces of the aircraft). They also do some computer work, which occurs during shorts periods of time all over the journey. In order to evaluate shoulder and neck symptoms a standardized physical examination was carried out [6]. Even though this protocol has been used to assess the whole upper limb, we have focused on shoulders and neck. Subjects with 11 or 
more positive items were classified as symptomatic while subjects with less than 11 positive items were labelled as asymptomatic. Psychosocial indicators were based on the Brazilian version of the Job Content Questionnaire (JCQ) [10] and Utrecht Work Engagement Scale (UWES) [17]. Results were compared between asymptomatic and symptomatic subjects through Chi-Square and Mann Whitney (number of positive items of the physical examination, raw JCQ and UWES scores) tests. All tests were run in Statistica (v. 7.2) software with alfa level set at 0.05 .

\section{Results}

According to the physical examination, 50 workers were classified as asymptomatic (AS - 4.1 \pm 3.17 positive signs) whilst 30 workers have presented more than 11 positive signs in the physical assessment of neck and shoulders (symptomatic subjects, SS - 26.72 \pm 11.44 positive signs). The number of positive signs was significantly different between AS and SS $(p=0.000)$. AS and SS have shown similar profile of demand $(p=0.62)$, control $(p=0.66)$ and social support $(p=0.74)$ according to the JCQ (see Table 1). However, the groups are different when considering work engagement variables $40 \%$ of AS were classified with high engagement while $60 \%$ of SS have high level of engagement). These results are demonstrated in Table 2.

Table 1. JCQ data among asymptomatic (AS) and symptomatic (SS) workers: raw data, percentages of each level (high and low) for demand, control and social support, and p-value of statistical comparisons.

\begin{tabular}{|c|c|c|c|}
\hline JCQ & AS (\%) & SS (\%) & $p$-value \\
\hline \multicolumn{4}{|l|}{ Demand } \\
\hline **Raw score & 14.36 & 14.73 & 0.62 \\
\hline High & 60.00 & 50.00 & \multirow{2}{*}{0.38} \\
\hline Low & 40.00 & 50.00 & \\
\hline \multicolumn{4}{|l|}{ Control } \\
\hline **Raw score & 16.42 & 16.06 & 0.66 \\
\hline High & 54.00 & 53.33 & \multirow{2}{*}{0.95} \\
\hline Low & 46.00 & 46.67 & \\
\hline \multicolumn{4}{|l|}{ Social Support } \\
\hline **Raw score & 19.78 & 20.13 & 0.74 \\
\hline High & 62.00 & 60.00 & \multirow{2}{*}{0.86} \\
\hline Low & 38.00 & 40.00 & \\
\hline \multicolumn{4}{|l|}{ Workers' Profile } \\
\hline Active & 34.00 & 30.00 & 0.71 \\
\hline Passive & 20.00 & 20.00 & 1.00 \\
\hline Low strain & 20.00 & 23.33 & 0.72 \\
\hline High strain & 26.00 & 26.67 & 0.94 \\
\hline
\end{tabular}

** Raw score is presented as mean value

Table 2. UWES data among asymptomatic (AS) and symptomatic (SS) workers: raw scores, percentages of each level (very low, low, mean, high and very high) for vigor, dedication, absorption and engagement domains, and p-value for statistical comparisons.

\begin{tabular}{|c|c|c|c|c|c|c|c|}
\hline UWES & AS (\%) & SS (\%) & $p$-value & & AS (\%) & SS (\%) & $p$-value \\
\hline Vigor & & & & Absorption & & & \\
\hline **Raw score & 4.90 & 5.42 & $0.02 * *$ & **Raw score & 4.40 & 4.91 & $0.03 * *$ \\
\hline Very low & 0.00 & 0.00 & - & Very low & 2.00 & 0.00 & 0.43 \\
\hline Low & 10.00 & 0.00 & 0.07 & Low & 4.00 & 0.00 & 0.26 \\
\hline Mean & 20.00 & 6.67 & 0.10 & Mean & 44.00 & 23.33 & 0.06 \\
\hline High & 48.00 & 46.67 & 0.90 & High & 46.00 & 60.00 & 0.22 \\
\hline Very high & 22.00 & 46.67 & $0.02 *$ & Very high & 4.00 & 16.67 & $0.05^{*}$ \\
\hline Dedication & & & & Work Engagement & & & \\
\hline **Raw score & 4.64 & 5.05 & 0.08 & **Raw score & 4.65 & 5.13 & $0.04 * *$ \\
\hline Very low & 4.00 & 0.00 & 0.26 & Very low & 0.00 & 0.00 & - \\
\hline Low & 10.00 & 3.33 & 0.27 & Low & 8.00 & 0.00 & 0.11 \\
\hline Mean & 38.00 & 20.00 & 0.09 & Mean & 30.00 & 16.67 & 0.18 \\
\hline High & 26.00 & 63.33 & $0.00 *$ & High & 40.00 & 60.00 & 0.08 \\
\hline Very high & 22.00 & 13.33 & 0.33 & Very high & 22.00 & 23.33 & 0.89 \\
\hline
\end{tabular}

$*$ Chi-Squared test, $\alpha=0.05$

** Raw score is presented as mean value, statistical comparison through Mann Whitney test, $\alpha=0.05$ 


\section{Discussion}

This study evaluated the psychosocial indicators among people, with and without neck and upper limb symptoms, working on aircraft maintenance perform material handling tasks. The results show that symptomatic workers have the same profile of demand and control as asymptomatic workers. However, they are more engaged to the work than asymptomatic subjects. It is an interesting result and may be related to the presence of both psychosocial and biomechanical risk factors. Marras et al. (2000) suggested that biomechanical factors, when present, overlap the involvement of psychosocial influences in the development of low back pain. We may suggest that in the presence of biomechanical risk factors, subjects that are more involved to their work are more exposed to risk factors and, thus, more susceptible to the development of musculoskeletal symptoms and disorders. Even though this theory has been suggested considering the low back pain, the lifting of heavy loads, awkward postures and repetitive effort are also related with disabling shoulder pain [4]. There is a vast literature that demonstrates the risks for the development of musculoskeletal disorders present in manual handling $[11,1,7,16,18,14,13,2]$. Kemp et al. (2010) evaluated handling tasks among civilian and military U.S. Air Force (USAF). They observed that the handling of aircraft components, boxes and furniture were associated with injuries (prevalence of $33 \%$ ) and a high number of absenteeism.

Some studies show that psychosocial factors such as low commitment, low job satisfaction, poor social support, low demand and low decision-making are associated with the development of musculoskeletal disorders [5, 9]. Therefore, when evaluating engagement it is important to consider that the greater the engagement, the lower the risk for musculoskeletal disorders. On the other hand, when the engagement is associated with the high need for approval, the risk for musculoskeletal disorders is increased [3]. It shows the importance of exploring the social context of psychosocial aspects in future studies involving this population.

In order to achieve more conclusive results, studies involving the evaluation of biomechanical risk factors as well as physical exposure of workers are necessary. Moreover, the complex interaction between psychosocial demand of the aviation sector and musculoskeletal disorders must be investigated.

\section{References}

[1] A.B. Oliveira, Biomechanical and ergonomic aspects of cargo handling activity with emphasis on the upper limb. Doctoral Dissertation. Graduate Program in Physical Therapy, Federal University of Sao Carlos, Sao Carlos, Brazil. 2008.

[2] A.K. Burton, K.M. Tillotson \& J.D.G. Troup, Prediction of the low-back trouble frequency in a working population. Spine, 1989; 14: 939-946.

[3] G.A.M. Ariens, W. van Mechelen, P.M. Bongers, L.M. Bouter, G. van der Wal, Psychosocial risk factors for neck pain: a systematic review. Am J Ind Med, 2001; 39:180-193.

[4] H. Miranda, L. Punnett, E. Viikari-Juntura, M. Heliövara, P. Knekt, Physical work and chronic shoulder disorder. Results of a prospective population-based study. Ann Rheum Dis. 2008; 67(2): 218-23.

[5] J.D. Nahrgang, D.A. Hofmann, F.P. Morgeson, Safety at Work: A Meta-Analytic Investigation of the Link Between Job Demands, Job Resources, Burnout, Engagement, and Safety Outcomes. Journal of Applied Psychology, 2011; 96(1):71-94.

[6] K. Ohlsson, R.G. Attewell, B. Johnsson, A. Ahlm, S. Skerfving, An assessment of neck and upper extremity disorders by questionnaire and clinical examination. Ergonomics, 1994; 37:891-897.

[7] K.P. Martimo, Verbeek J, Karppinen J, Furlan A D, Kuijer PPFM, Viikari-Juntura E, Takala EP, Jauhiainen M, Manual material handling advice and assistive devices for preventing and treating back pain in workers (Review). The Cochrane Collaboration. 2007.

[8] L.M. Straker, An overview of manual handling injury statistics in Western Australia. International Journal of Industrial Ergonomics, 1999; 24 (4): 357-64.

[9] M. Coetzee, M. Villiers, Sources of job stress, work engagement and career orientations of employees in a South African fi nancial institution. Southern African Business Review, 2010;

14(1): $27-58$

[10] M.G.M. Alves, D. Chor, E. Faerstein, C.S. Lopes, G.L. Werneck, Versão resumida da "job stress scale": adaptação para o português. Revista de Saúde Pública, 2004; 38(2): 164-171.

[11] P.A. Kemp, B.R. Burnham, B. Copley, M.J, Shim. Injuries to Air Force Personnel Associated with Lifting, Handling, and Carrying Objects. Am J Prev Med, 2010; 38(1S):S148-S155.

[12] R. Caillet, Síndrome da dor lombar, 5a ed, Porto Alegre: Artmed. 2001, 81-96.

[13] S. Kumar, Y. Narayan \& M. Zedka, Trunk strength in combine motions of rotation and flexion extension in normal adults. Ergonomics, 1998; 41: 835-852.

[14] S. Nadeau, M. Gangnon, Work and energy transfers in maximal pushing of loads. International Journal of Industrial Ergonomics, 1996; 17:221-234.

[15] S. Thorn, Muscular activity in light manual work - with reference to the development of muscle pain among computer users. Doctoral Thesis.Chalmers University of Technology, Göteborg, Sweden. 2005

[16] S.S. Yeung, A. Genaidy, J. Deens, A. Alhemood, P.C. Leung, Prevalence of musculoskeletal symptoms in single and multiple body regions and effects of perceived risk of injury among manual handling workers. Spine, 2002; 27(19): 2166-2171. [17] W. Schaufeli, A. Bakker, UWES: Utrecht Work Engagement Scale. User's Manual. Occupational Health Psychology Unit, Utrecht University. 2003.

[18] W.S. Marras, Occupational low back disorder causation and control. Ergonomics, 2000; 43(7): 880-902. 